\title{
Intercultural postgraduate supervision: Post-colonial explorations and reflections on Southern positionings
}

\section{Catherine ManAThunga}

\section{Abstract}

Opportunities for intercultural supervision have increased in recent years with more international enrolments in Western countries and more participation of culturally diverse and indigenous students in research higher degrees. While the burgeoning literature on intercultural supervision is helpful, it does not address the complex and rewarding issues of power and identity that emerge when supervisors and students from different cultures work together. This article argues that post-colonial theory offers critical insights into the pleasures and tensions of intercultural supervision, building upon data collected from an Australian university. It also investigates the possibilities offered to supervisors and students working in the global South to work towards decolonising knowledge and methodologies.

$\mathrm{O}$ pportunities for supervisors and students from different cultures to work together have increased in many Western universities as more international students enrol in research higher degree programmes outside of their home countries, and as more culturally and linguistically diverse and indigenous students gain access to higher degree study. At the same time, there has been a proliferation of guidebooks and research on intercultural communication and supervisory pedagogical strategies to assist supervisors and students engaged in intercultural supervision (e.g., Ballard \& Clanchy, 1991; Denholm \& Evans, 2007). While much of this literature has moved beyond the deficit approaches common in some of the early literature (e.g., Ballard \& Clanchy, 1991), there is still a focus on positivist and interpretativist explanations of the dynamics of intercultural 
supervision. In particular, these contributions do not address the complex, challenging and rewarding issues of power and identity that circulate in any form of supervision but that are often compounded and enhanced in intercultural supervision.

This article seeks to contribute to the growing body of work exploring intercultural supervision using post-colonial theoretical frameworks that allow us to raise issues about the operations of history, power and identity in intercultural supervision. Indeed, much of this work comes out of Aotearoa New Zealand and focuses on Māori supervision of and by Māori (Grant, 2010; Grant \& McKinley, in press; McKinley, Grant, Middleton, Irwin, \& Williams, 2011; Middleton \& McKinley, 2010). My approach to post-colonial theory draws on literary and historical disciplinary understandings of these theories, which map onto my own intellectual and disciplinary histories. In particular, I have drawn upon the understandings of Homi Bhabha, Stuart Hall, Mary Louise Pratt and Linda Tuhiwai Smith. I have also been influenced by revisionist histories that became common in post-colonial nations in the last few decades, particularly relating to Irish history which was the focus of my honours and PhD research. In particular, my article demonstrates the usefulness of the post-colonial tropes or concepts of assimilation, unhomeliness and transculturation in helping us to rethink intercultural supervision and the ways in which history shapes supervisory interactions and power dynamics.

This paper draws upon data collected at an Australian university which particularly examined the supervision of international and domestic culturally and linguistically diverse research students. While it does not incorporate data on the supervision of Aboriginal and Torres Strait Islander students, it draws upon some of the insightful post-colonial investigations of Māori supervision from Aotearoa New Zealand (Grant, 2010; Grant \& McKinley, in press; McKinley et al., 2011; Middleton \& McKinley, 2010). As an Irish-Australian researcher who has recently migrated to Aotearoa New Zealand for work, the ways in which I have grappled with post-colonial theory are powerfully shaped by the Australian context in which this study was conducted. There are significant differences in the Aotearoa 
New Zealand context, which I will be unable in the space allowed for this article to fully address. Instead I have sought, where possible, to draw upon the work listed above on Māori supervision to make this paper relevant to the Aotearoa New Zealand context. With slowly increasing numbers of Māori and Pasifika supervisors and an increase in recent years in Aotearoa New Zealand in the numbers of Māori and Pacific Islander research students (391 or $7.8 \%$ and 141 or $2.8 \%$ respectively in 2009, MOE Education Counts website $^{1}$ ) and international research students ${ }^{2}$, I hope that enhanced understandings of the dynamics of intercultural supervision will translate into improved completion rates for these students.

This article also begins to speculate on how being located in the global South might offer supervisors and students different possibilities to grapple with the ongoing domination of Western knowledge and methodologies in many disciplines. In using terms like global South/North, Eastern/Western and indigenous/non-indigenous, I am seeking to capture the power traditionally accorded to knowledge developed in the colonial metropole continents of Europe and North America as opposed to that developed in Asian countries and in colonial peripheries like Australia and Aotearoa New Zealand (Connell, 2007; Smith, 1999). This article explores how we might use the unresolved post-colonial tensions evident in our societies in Australia and Aotearoa New Zealand to engage with our diverse students to reposition knowledge and methodologies and create new spaces for Southern, Eastern and indigenous knowledges and methodologies. I have described my position as an Irish-Australian researcher in terms of being a settler/invader scholar. This is because we have no succinct term to capture colonialisation in the Australian context. There is no equivalent term to that of Pākehā or Palagi scholar used in the Māori and Samoan languages. The closest in Queensland (where I have lived most of my life) might be 'migaloo' which my Murri ${ }^{3}$ colleagues use to describe white people, but I do not think this sufficiently captures the operations of power and dispossession in Australia. I also outline my speculations about how I might engage with my culturally and linguistically diverse students to work towards the building of Southern, decolonised theory. Although 
the huge categories of Western/Northern/non-indigenous and Southern/Eastern/indigenous are highly problematic, I wish to draw upon them in this article to grapple with how the Southern location of Australia and Aotearoa New Zealand might offer us particular opportunities to decolonise knowledge and methodologies. There will also be times when I use equally problematic terms such as Asian or African or South American to describe students or supervisors. This is done in order to protect the anonymity of participants and the supervision relationships between participants.

\section{Intercultural supervision}

The impact of globalisation and aggressive marketing by universities in many countries has increased the flow of international or culturally diverse students enrolling in postgraduate research higher degree programmes outside their own countries. Furthermore, as access to postgraduate education widens, more local culturally diverse and indigenous students enrol in research higher degree studies. Trends in mobile scholarship have also increased, with academic staff becoming more likely to move between countries and universities. There have also been epistemic challenges to the dominance of Western/Northern knowledge and theory (Connell, 2007; Smith, 1999).

The supervision of research students does not take place in a disembodied vacuum where a less academically trained brain somehow absorbs the knowledge, critical and creative insights of one or several more experienced and credentialed minds. Culture plays an intrinsic part in all research and knowledge construction, even in disciplines such as Science and Engineering. As I have demonstrated elsewhere, there are multiple layers of culture involved in research and in research education - the ethnic cultures of the researchers and their participants or objects of study; [inter]disciplinary research cultures; university, government, industry and community cultures; individual workplace cultures and so on (Manathunga, 2009). In supervision, we prepare research students to work across and between many cultural contexts in the contemporary world of research. 
And yet many of the dominant discourses about supervision ignore the role of culture in supervision. The older discourse about supervision as a form of osmosis between the minds of two people persists in more recent discourses about supervision as cognitive interaction. In this traditional construction of supervision, research students lurked in the shadows of the 'God Professor' (Dale, 1997), hoping that his genius would rub off on them enough to be one day credentialed as a 'Doctor of Philosophy'. Not only was there an absence of a sense of explicit pedagogy inherent in this discourse, but the body with its cultural and gendered inscriptions is an 'absent present' (present but not acknowledged). Bodies of difference, such as those of women and culturally diverse people, either did not play a role, or at the very least were accorded a subservient role.

In the old days supervision was between two minds - only one supervisor - whereas we now have team supervision, so in the more recent project management discourse supervision is perceived to take place between two or three equally powerful minds - one novice and one or several more experienced now that we have team supervision who carefully construct a tidy Gantt chart outlining the logical, sequential steps required to bring the student's research project to an inevitable and successful completion. Such a construction of supervision excludes the unpredictable, creative or surprising outcomes and obstacles possible in research. Something as complex and messy as culture does not belong in this neat supervision picture. This dominant discourse is particularly aligned with disciplines, such as Science, Health Sciences and Engineering in the Australasian context, where knowledge construction is perceived to be rational and objective. Even though there is an increasing proportion of international and culturally diverse research students enrolling in these disciplines, culture is not recognised as playing a part in supervision. I once asked an audience of supervisors and students from Health Science in Australia, who were clearly from many diverse ethnicities, what role culture played in their research, and they were unable to answer me. 
In intercultural supervision or supervision where people from two or more different cultures are working together, the bodies involved are often more clearly inscribed with difference, with diverse cultures and histories, hailing sometimes from different geographies. Very often, in intercultural supervision, culture is not something that can be easily ignored or forgotten in the pursuit of new knowledge and the socialisation of research students into disciplinary, or increasingly interdisciplinary, cultures. However, even the studies of intercultural supervision that provide practical tips about useful communication and pedagogical strategies (e.g., Ballard \& Clanchy, 1991; Denholm \& Evans, 2007) do not tackle the more challenging issues of power, identity and culture present in supervision. While this material has provided supervisors, students, and university and government policy makers with helpful ideas and strategies, a coherent, theoretically grounded investigation of power, identity and culture in supervision is required to advance our understandings of intercultural supervision.

This is where post-colonial theory becomes particularly useful because it allows us to investigate the ways in which colonial discourses continue to dominate intercultural interactions and the construction of knowledge and methodologies in many disciplines. In intercultural supervision, there may be times when colonially-written scripts about a hierarchy of cultures or ways of thinking and being may interfere even subconsciously in supervision pedagogy. Particularly in supervision relationships between indigenous students and non-indigenous supervisors, as the work of Grant and McKinley has shown (e.g., Grant, 2010; Grant \& McKinley, in press), unresolved colonial histories, transgressions, and guilt intrude into supervision in complex ways. These colonially written scripts can also have different, but no less real, impacts upon the supervision of students from Asian, African, Middle Eastern, Pacific and South American countries (e.g., Bullen \& Kenway, 2003).

While a substantial amount of poststructuralist research into postgraduate supervision has begun to uncover the disruptive and productive role of the body in supervision pedagogy (e.g., Middleton \& McKinley, 2010), new theoretical resources are required to further unpack the role of culture, time and place in intercultural supervision. 
In particular, understanding the complex ways in which prior colonial scripts may continue to frame intercultural supervision requires a great deal more investigation.

\section{Post-colonial theories}

Post-colonial theory allows us to gain critical and fresh insights into the complexities and pleasures of intercultural supervision for both students and supervisors. I think that post-colonial theory enables supervisors and students to bring a sense of history into experiences of supervision. Supervision pedagogy, like any form of teaching and learning, is not an entirely rational, conscious or neutral intellectual zone. We do not leave our identities behind when we engage in supervision. Instead, our personal histories, experiences, cultural and class backgrounds, and social, cultural and national locations remain present (some might say omnipresent) as we engage in the supervisory process. Culture, politics and history matter in supervision.

Because our world has been so profoundly shaped by colonialism and neo-colonialism in so many forms, our own personal positioning in relation to colonialism has an impact on our personal and professional ways of thinking, being and supervising. Each student and supervisor will have complex and often contradictory positionings in relation to that history of colonisation. I, for example, have such a contradictory positioning as an Irish-Australian woman. I am a descendant of the colonised people of Ireland and one of the nonindigenous people who colonised the settler/invader nation of Australia.

In my work on intercultural supervision, I have particularly found the post-colonial tropes or concepts of assimilation, unhomeliness and transculturation powerful in seeking to uncover the complex operations of history, power and identity in supervision. As a result of the personal and professional history of individual supervisors and students and of the Western construction of disciplinary knowledges and epistemologies, students from diverse cultural backgrounds may experience assimilation in their studies (Manathunga, 2007). The Penguin Dictionary of Sociology (Abercrombie, Hill, \& Turner, 1984) defines assimilation as a "unidimensional, one-way process by which 
outsiders relinquished their own culture in favour of that of the dominant society" (p. 14). Post-colonial theorists have used the related concepts of Euro-centrism and Universalism (Ashcroft, Griffiths, \& Tiffin, 2000). I have applied this concept to intercultural supervision, locating in my preliminary study some instances when supervisors ignored any prior cultural knowledge students might bring to their studies and required students to fully conform with Western/Northern research approaches (Manathunga, 2007, 2011).

The challenges of working across and between cultures in supervision can also produce moments of ambivalence or unhomeliness for both supervisors and students (Manathunga, 2007, 2011). Unhomeliness is a post-colonial concept that allows us to think about how "the cultural alienation, sense of uncertainty and discomfort that people experience as they adjust to new cultural practices” (Manathunga, 2007, p. 98) can impact on supervision. This is particularly significant for students from diverse cultural backgrounds as they engage with alien cultural and institutional contexts, different educational systems, and unwritten assumptions or expectations supervisors may have of them (Manathunga, 2011). It may also emerge for supervisors who may need to adopt different and unnatural supervision styles (e.g., Cadman \& Ha, 2001). In supervising indigenous or Eastern students, supervisors may also have to accept that there is a great deal that they do not or cannot know, as Grant's (2010) research on Māori supervision highlights and as Singh's (2009) study of the productiveness of cross-cultural ignorance demonstrates. In these cases, the supervisor becomes the unauthorised and unknowing 'Other'.

While the weight of all this history brings additional complexities and tensions to intercultural supervision, it can also produce exciting, deconstructive possibilities and innovations (Grant, 2010; Manathunga, 2007; Singh, 2009). I have applied the post-colonial construct of transculturation to investigate this positive feature of intercultural supervision (Manathunga, 2007). I wrote about transculturation in supervision pedagogy as moments of creativity when "culturally diverse students may carefully select those parts of Western knowledge that they find useful and seek to blend them with 
their own knowledge and ways of thinking” (pp. 97-98). Ravinder Sidhu (2006) also talks about opportunities for this kind of transculturation in her broader study of international education.

Moments of transculturation can also be experienced by supervisors in intercultural supervision relationships. As Venables, Ahjum, and De Reuck (2001) explain, with every new supervision the supervisor as well as the student engages in identity work. This means that supervisors' identities may shift and change as part of their engagement with culturally diverse students and their Eastern/ indigenous/Southern ways of thinking, knowing and being (Manathunga, 2007). Even if this unsettles their sense of supervisory subjectivity and their sense of authority, these experiences of transculturation may help the supervisor to expand their ways of understanding the world, to rethink their disciplinary knowledge and epistemologies, and to remain humble in the process of themselves continuing to become learners (Grant, 2010; Singh, 2009).

\section{Research context and methodology}

I have applied these three post-colonial tropes to some data I collected during two studies of intercultural supervision in the Humanities, Social Sciences and Sciences at an Australian research-intensive university. I conducted a pilot study in the Humanities and Social Sciences in 2007 (Manathunga, 2007) and then a larger study was carried out in the Sciences as well as the Humanities and Social Sciences in 2009 and 2010, with research assistance from Dr Maryam (Shirin) Jamarani and Dr Suzanne Morris (Manathunga, 2011). In total across both studies, 22 supervisors, who identified as Chinese, Japanese, Spanish, English, and Australian, and 25 students, who were Vietnamese, Malaysian, Mexican, Bangladeshi, Italian, German, Chinese, Iranian, Indonesian, and Thai were interviewed. Standard ethical clearance was obtained from the participating university and interviews were conducted using a semi-structured approach. The purpose of the research was to investigate how history, culture and identity played out in supervisors' and students' constructions of their experiences of intercultural supervision. A thematic analysis was carried out on these data, using the post-colonial metaphors of 
assimilation, unhomeliness and transculturation. In this article, I will briefly illustrate how these post-colonial tropes play out in three snapshots from my data from the Humanities and Social Sciences and Engineering. Quotations listed below refer to the statements participants made in interviews. More details about the examples of unhomeliness and transculturation are available in other publications (Manathunga, 2007, 2011).

\section{Moments of assimilation, unhomeliness and transculturation}

There were clear moments of assimilation in the supervision of an Asian student by two Australian supervisors in my data from the Social Sciences. In this case, one of the Australian supervisors in that early study (Manathunga, 2007) refused to accept that her Asian student brought any useful knowledge or expertise with him. Even though she indicated that it was "good" to find out more about his approaches to their practitioner field, she was very quick to quash his ideas about research:

And I was saying to him "you can't do that", and he said "that is the one I want to use." I am going "NO, what you've got to do is you have to", and he began to understand why he needed to do that. (Australian supervisor interview, 2007)

The student experienced this as "some sort of restriction to voice everything to her” (Asian student interview, 2007). This contrasted with his interactions with his other supervisor who commented: "I feel more at ease with her. I try to express my feelings. And sometimes express my ideas with her. And I know that she would not be judgemental and she would be accommodating to me” (Asian student interview, 2007).

There are also many unhomely moments present in these data. For example, one Engineering English male supervisor argued that he has learnt to be more directive in his supervision of international students as a result of his earlier experiences with an Asian student. He currently supervises a student from South America and aims to be "more prescriptive at the start ... and more structured and to give them 
more instructions at the start and then gradually try to give them more independence" (English supervisor, interview 2009). This is, however, an unhomely experience for his student. On the one hand she appreciates the extra support that he offers her, but is troubled by the "very paternal kind of way" he treats her. She exclaims, "I don't know, maybe people have the impression that we are slower, or something... I have the sense that they have more confidence with the domestic [students]" (South American student, interview 2009) (for more details, see Manathunga, 2011).

Finally, there are also instances of creative transculturation where students actively seek to combine the aspects of Western knowledge they find useful with their own cultural knowledge in order to create innovative arguments or approaches. For example, an Asian female supervisor, who had completed her doctoral studies and then spent the next 25 years as an academic in Australia, reflected on her experience of doctoral studies. She spoke about the challenges she faced as a doctoral student in reconciling her Asian values about collectivity, reciprocity and holistic connections between her mind, body and spirit with Western approaches to research that focus principally on the individual and the mind. It was only when she came across largely Western postmodernist theories about identity and subjectivity (which were relatively new at the time) that she was able to creatively blend these theories with her own Asian values to produce her original contribution to knowledge (see Manathunga, 2007 for more detail).

\section{Reflections on decolonising methodologies and knowledge in the South}

For some time now I have been speculating on what possibilities and tensions my positioning as a settler/invader scholar in the Southern location of Australia offers. As indicated at the beginning of this article, I have chosen to use this term to try and capture the postcolonial positioning of non-indigenous people who arrived in Australia in the absence of commonly accepted terms like those used in Aotearoa New Zealand (Pākehā or Palagi). The term settler masks the violence and problematic nature of European colonisation of Australia, while the notion of invasion remains a controversial concept 
for many Australians. Unlike Aotearoa New Zealand, there was never any treaty signed in Australia and much of this terrible colonial history has never really been acknowledged, processed, or dealt with. So I need to use the terms settler/invader simultaneously. As a recent migrant worker (albeit with more cultural capital than many migrant workers) in Aotearoa New Zealand, I feel that this will add a new dimension to my research on supervision and my efforts to support my culturally diverse students to challenge the dominance of Western knowledge and methodologies.

Of course, this unprocessed and continuing history of marginalisation, oppression and symbolic and at times actual violence in settler/invader societies particularly impacts upon indigenous students in postgraduate supervision. A number of authors demonstrate how this plays out in challenging and rewarding ways in Māori supervision in post-colonial Aotearoa New Zealand (Grant, 2010; Grant \& McKinley, in press; McKinley et al., 2011; Middleton \& McKinley, 2010). However, as indicated above, colonial discourses also may continue to shape Western supervisors' interactions with other culturally and linguistically diverse students, which have been the focus of my studies in Australia.

So I have been investigating the ways in which the intercultural supervision we engage with in Australia and Aotearoa New Zealand could become Southern or decolonising. Certainly the dominant research paradigms that continue to enjoy pre-eminence in many disciplines and interdisciplines in both of these countries are Western, although Māori and Aboriginal and Torres Strait Islander researchers have managed to challenge this (e.g., Ford, 2010; Smith, 1999). I think countries like Australia and Aotearoa New Zealand are uniquely placed to challenge the dominance of Western theory. In particular, as supervisors, I think we can work to support our students from Southern, Eastern and indigenous cultures to push the boundaries of what counts as knowledge in our disciplines. Although this is not unproblematic, as a number of authors have pointed out (e.g., Grant, 2010; Grant \& McKinley, in press; McKinley et al., 2011; Middleton \& McKinley, 2010), it is still important if we are to eventually create Southern theory and decolonise methodologies. It would have to 
involve a huge shift in the policies and practices of knowledge gatekeepers in universities, governments and other sites of knowledge creation so that students and, at times, their supervisors were not exposed to the continuing operations of institutional racism and discrimination. It would also involve working out how university supervisors and their Southern, Eastern and indigenous students might grapple with a respectful engagement with these knowledges that reside within Southern, Eastern and indigenous knowledge communities. This would involve formulating conditions under which these knowledge communities might grant permission, legitimacy and authority to university supervisors and students.

A really intriguing example of this work can be found in a forthcoming book chapter written by Singh from the University of Western Sydney in Australia. Having already established a place for what Singh (2009) calls the pedagogy of ignorance (where Western supervisors recognise the limitations of their knowledge of other cultures), he then extends this work by outlining how some of his Chinese students are challenging current Western knowledge by drawing upon their Chinese intellectual heritage, their multilingual abilities and their transnational digital communities (Singh, in press). In instances that I would call transculturation, Singh's students seek to connect intellectual developments in studying school pedagogy in China with those taking place in Australia. This involves a four-step process of conceptualising by taking a literal translation of a Chinese character (kunji), contextualising the historical and contemporary use of this character, using this Chinese concept to challenge Western knowledge, and finally making transnational intellectual connections demonstrating how Chinese concepts can provide new understandings of pedagogy. For example, one of his students (who has co-written this part of the book chapter with him) developed the concept from Chinese of $l i$ ti (upright body with length, width and thickness - 3 dimensional) leadership in schools in order to better capture the multidimensional nature of leadership where different school, regional and system-based partners are operating across and between these 
levels in unevenly distributed ways. This extended the Western concept of tri-level leadership, which failed to adequately capture the complexity of these partnerships (Singh, in press).

A forthcoming book chapter by Grant and McKinley on Māori doctoral supervision describes the Māori concept of pedagogy which is called ako. Ako is the Māori word for the concept that constructs pedagogy as the "unified cooperation of the learner and the teacher in a single enterprise" (Grant \& McKinley, in press, p. 3). There are three traditional forms of ako that could be adapted to Māori supervision. These are formal learning, everyday exposure, and apprenticeship. Each of these approaches is usually conducted in a 'proper setting' (in other words place is really important) with the learner listening, looking, and imitating with a minimum of words, and may involve a series of tests to check the learner's desire to learn. Grant and McKinley (in press) demonstrate how these pedagogies require time, care, Māori cultural knowledge and language development and recovery, and call on institutions to make space in their research higher degree programmes to facilitate these slower and deeper doctoral pedagogies. These pedagogies are also usually applied in the context of Māori students wishing to strengthen their Māori identity by carrying out Māori-related research.

In particular, I had been thinking about how my positioning as an Irish-Australian settler/invader supervisor could be used to work with my culturally diverse research students to create southern knowledge and methodologies in Australia. I have yet to reimagine what this might involve as a migrant worker in Aotearoa New Zealand. To date in the Australian context, I imagined that I would need to do the following in order to work towards a Southern post-colonial form of intercultural supervision:

- seek to understand more about indigenous and Eastern forms of knowledge and how they can and do reshape my field of education and my discipline of history 
- actively create spaces in my academic work and school for Aboriginal and Torres Strait Islander, Eastern and Southern academics, scholars, students (especially research higher degree students), elders and community members

- always remember that settler/invader identities are working from a position of power and dominance (Moran, 2002) and constantly think about what Alison Jones (1999) calls our inability to hear the voices of the marginalised and what Michael Singh (2009) calls our ignorance

- learn that sometimes we cannot fully know Aboriginal and Torres Strait Islander, Māori, Pacific Islander peoples' or Eastern history and culture. Alison Jones (1999) reminds us to "to embrace positively a 'politics of disappointment' that includes a productive acceptance of the ignorance of the other" and a "gracious acceptance of not having to know the other" (pp. 315-6).

\section{Conclusion}

Therefore, I have argued that post-colonial theory enables supervisors and students to recognise and grapple with the complex issues of power, culture and history that may emerge as they engage in intercultural postgraduate supervision. These theories, particularly those that investigate the tropes of assimilation, unhomeliness and transculturation, allow supervisors and students to understand the pleasures and perplexing tensions that may occur in intercultural supervision. These types of rich and deep understandings are unlikely to emerge from reading the literature that portrays supervision as an unproblematic project management exercise or as merely a matter of establishing clear, explicit communication.

This article also reminds us that the unfinished business of Western colonial scripts continues to reverberate not only in interactions between indigenous students and non-indigenous supervisors, but also in intercultural supervision between culturally diverse Eastern and Southern students and Western supervisors. Supervisors' and students' own personal histories and positioning in relation to colonisation may also be ambiguous and contradictory. However, the unique 
opportunity indigenous, Eastern and Southern students have to work across and between cultural boundaries and knowledges also produces exciting deconstructive possibilities and innovations. The production of creative transcultural knowledge has the potential to push the borders of disciplines into intriguing new cultural spaces.

I have also reflected on whether our Southern positioning in postcolonial societies like Australia and Aotearoa New Zealand offers us additional opportunities to work towards decolonising methodologies, as Smith (1999) encourages us to do and as Māori and Aboriginal and Torres Strait Islander researchers have already begun to do. In grappling with our location as settler/invader or Pākehā or Palagi scholars situated in post-colonial societies, do we not have a special responsibility to challenge the dominance of Western and Northern theory-making through our own research and through our supervision of indigenous, Eastern and Southern research students? In making this argument, I have highlighted two intriguing examples from Aotearoa New Zealand and Australia where supervisors are encouraging their Māori and Chinese students to work in this way.

Finally, I have tried to list some of the ways in which settler/ invader or Pākehā or Palagi supervisors might work towards implementing a Southern post-colonial form of intercultural supervision. Such a post-colonial intercultural supervision philosophy would seek to understand and respect indigenous, Eastern and Southern forms of knowledge and create spaces for students and scholars from these cultures to decolonise methodologies and build Southern theory and knowledge, while, at the same time, remaining cognisant of the very real power and privilege settler/invader or Pākehā or Palagi scholars continue to have in the academy.

\section{Acknowledgements}

Some of this material was first presented as a keynote presentation at the Postgraduate Supervision Conference at Stellenbosch University in South Africa in April 2011. I would also like to thank the reviewers for their helpful comments, especially those helping me to orientate this article more towards the Aotearoa New Zealand context. 


\section{References}

Abercrombie, N., Hill, S., \& Turner, B. (1984). The Penguin dictionary of sociology (4th ed.). London: Penguin Books.

Ashcroft, B., Griffiths, G., \& Tiffin, H. (2000). Post-colonial studies: The key concepts. New York: Routledge.

Ballard, B., \& Clanchy, J. (1991). Teaching students from overseas: A brief guide for lecturers and supervisors. Melbourne: Longman Cheshire.

Bullen, E., \& Kenway, J. (2003). Real or imagined women? Staff representations of international women postgraduate students. Discourse: Studies in the Cultural Politics of Education, 24(1), 35-50.

Cadman, K., \& Ha, H. T. (2001). 'Only connect': Transcultural supervision as the 'Rainbow Bridge'. In A. Bartlett \& G. Mercer (Eds.), Postgraduate research supervision: Transforming (r)elations (pp. 215-232). New York: Peter Lang.

Connell, R. (2007). Southern theory. Crows Nest, NSW: Allen \& Unwin.

Dale, L. (1997). The English men. Canberra: Association for the Study of Australian Literature.

Denholm, C., \& Evans, T. (Eds.). (2007). Supervising downunder. Camberwell, Victoria: ACER Press.

Ford, P. L. (2010). Aboriginal knowledge narratives and country: Marri Kunkimba Putj Putj Marrideyan. Brisbane: Post Pressed.

Grant, B. (2010). Challenging issues: Doctoral supervision in post-colonial sites. Acta Academica Supplementum, 1, 103-129.

Grant, B., \& McKinley, E. (in press). Expanding pedagogical boundaries: Indigenous students undertaking doctoral education. In A. Lee \& S. Danby (Eds.), Reshaping doctoral education: Changing programmes and pedagogies. London: Routledge.

Jones, A. (1999). The limits of cross-cultural dialogue: Pedagogy, desire and absolution in the classroom. Educational Theory, 49(3), 299-316.

Kenway, J., \& Bullen, E. (2003). Self-representations of international women postgraduate students in the global university 'contact zone'. Gender and Education, 15(1), 5-20.

Manathunga, C. (2007). Intercultural postgraduate supervision: Ethnographic journeys of identity and power. In D. Palfreyman \& D. McBride (Eds.), Learning and teaching across cultures in higher education (pp. 93-113). New York: Palgrave Macmillan. 
Manathunga, C. (2009). Research as an intercultural contact zone. Discourse: Studies in the Cultural Politics of Education, 30(2), 165-177.

Manathunga, C. (2011). Moments of transculturation and assimilation: Postcolonial explorations of supervision and culture. Innovations in Education and Teaching International, 48(4), 367-376.

McKinley, E., Grant, B., Middleton, S., Irwin, K., \& Williams, L. (2011). Working at the interface: Indigenous students' experience of undertaking doctoral studies in Aotearoa New Zealand. Equity \& Excellence in Education, 44(1), 115-132.

Middleton, S., \& McKinley, E. (2010). The gown and the korowai: Māori doctoral students and the spatial organisation of academic knowledge. Higher Education Research \& Development, 29(3), 229-243.

Moran, A. (2002). As Australia decolonises: Indigenising settler nationalism and the challenges of settler/indigenous relations. Ethnic \& Racial Studies, 25(6), 1013-1042.

Sidhu, R. (2006). Universities and globalisation: To market, to market. New Jersey: Lawrence Erlbaum.

Singh, M. (2009). Using Chinese knowledge in internationalising research education: Jacques Ranière, an ignorant supervisor and doctoral students from China. Globalisation, Societies and Education, 7(2), 185-201.

Singh, M. (in press). Generative ignorance, non-Western knowledge and the reshaping of doctoral education: Arguing over internationalising Westerncentred programmes and pedagogies. In A. Lee \& S. Danby (Eds.), Reshaping doctoral education: Changing programmes and pedagogies. London: Routledge.

Smith, L. T. (1999). Decolonising methodologies: Research and indigenous peoples. London: Zed Books.

Venables, E., Ahjum, S., \& De Reuck, J. (2001). 'The remembrance of things past': Memory and migration as tropes in the construction of postgraduate subjectivities. In A. Bartlett \& G. Mercer (Eds.), Postgraduate research supervision: Transforming (r)elations (pp. 233-246). New York: Peter Lang. 


\section{The author}

Catherine Manathunga is an Associate Professor in the School of Education Policy and Implementation in the Faculty of Education at Victoria University of Wellington. Her research interests focus on doctoral supervision pedagogy, doctoral graduate outcomes and attributes, interdisciplinarity, and the history of university teaching and learning in Australia and Aotearoa New Zealand.

Email: catherine.manathunga@vuw.ac.nz

1 See http://www.educationcounts.govt.nz/statistics

2 Recent MOE reports only present totals of all international students rather than only those doing their PhDs.

3 Murri is the term used by Aboriginal groups in Queensland and northern New South Wales. 